\title{
Evaluation of Reinforced Concrete Columns under Biaxial Bending
}

\author{
Mohammadreza Zarringol ${ }^{1} \&$ Mohammadehsan Zarringol $^{2}$ \\ ${ }^{1}$ Faculty of Science, Engineering and Technology, Swinburne University of Technology, Hawthorn, Australia \\ ${ }^{2}$ Geotechnical Engineering Department, University of Guilan, Rasht, Iran \\ Correspondence: Mohammadreza Zarringol, Faculty of Science, Engineering and Technology, Swinburne \\ University of Technology, Hawthorn, Australia. Tel: 61-4-1248-2791. E-mail: Zarringol_reza@yahoo.com
}

Received: December 6, 2016

Accepted: February 27, 2017

Online Published: March 30, 2017

doi:10.5539/jsd.v10n2p228

URL: https://doi.org/10.5539/jsd.v10n2p228

\begin{abstract}
Modeling by finite element method provides a ground for better perception of the behavior of reinforce columns and it is also useful in prediction of the behavior of these members without the experimental results. The performance improvement depends upon different parameters including the geometry of columns and configuration of reinforcement layers. In this study, slender reinforced columns are modeled under axial and biaxial bending loading with Carbon fiber reinforced polymer (CFRP) with different slender ratios using Abaqus software. The model is validated by the results of Bilchek et al., experiments. In this design, 30 concrete unstrengthened hoop columns with the diameter $100 \mathrm{~mm}$ and heights $200,400,600,800,1000 \mathrm{~mm}$ are made and reinforced with bidirectional CFRP composites. In each slenderness, a control sample (unstrengthened) and 5 reinforced specimens with different fiber configurations (hoop, longitudinal, angel and their combination) are tested under axial loading and biaxial bending to the ultimate failure. The results showed that these composites increased strength and ductility of specimens considerably. The results showed that in unstrengthened specimens, by increasing slenderness from 1 to 10 , strength and ductility were reduced as $35,65 \%$, respectively. The results showed that the modeling using experimental data had good consistency. Based on the shortage of experimental data in slender columns at big scale, by performing similar studies, the existing problems can be eliminated.
\end{abstract}

Keywords: sender reinforced concrete column, biaxial bending, finite elements analysis, Carbon Fiber Reinforced Polymers, Abaqus

\section{Introduction}

Strengthening concrete structures using traditional materials (concrete, rebar) as applied in the past increased the area surface besides the increase of bearing capacity. In recent decades, new composite materials have been found for strengthening. One of the most common applications of these composites is Carbon Fiber Reinforced Polymers (CFRP) and its highly applied reason is its features namely high strength-weight ratio, resistance against corrosion and easy access. The application of fiber reinforced polymers (FRPs) in strengthening concrete structures is extended to different stresses (loadings).

As study has been conducted in this regard by Mirmiran et al.. They tested Concrete-Filled Fiber-reinforced polymer Tube and observed considerable reduction in bearing capacity of column by the increase of slenderness ratio. CFFT columns were affected by slenderness ratio due to high strength and low stiffness of FRP materials compared to steel (Mirmiran, A., Shahawy, M., and Beitleman, T. 2001).

Pan et al., showed that the effect of strengthening was reduced by the increase of slenderness ratio as the effect of slenderness ratio on bearing capacity of FRP confined concrete columns is higher compared to that of non-confined columns and it is due to the increase of strength instead of the increase of bending stiffness by confinement (Pan, J.L., Xu, T., and Hu, Z.J. 2007).

The effect of increase of eccentric loading and slenderness of column on the reduction of CFRP confinement on the increase of bearing capacity was evaluated by Tao (Tao, Z., and Han, L. H. 2007). The results of experiments on confined concrete specimens by Tamuzs et al. Showed that tangent confinement increased bearing capacity only for columns with slenderness coefficient lower than 40(Tamuzs, V., Tepfers, R., Zile, E., and Valdmanis, V. 2007). The effect of strengthening square columns with unidirectional and bidirectional CFRP sheets with slenderness ratio of 70 was evaluated by Tao. The final strength of reinforced columns transversely had no considerable difference with unstrengthened columns (Tao, Z., and Yu, Q. 2008). 
Fitzwilliam showed the strengthening effect using CFRP, two or four layers in longitudinal and transverse directions on small scale specimens (columns with hoop cross section and slenderness 10-35). By the increase of column slenderness, due to the reduction of confinement effect, the bearing capacity of column was reduced (Fitzwilliam, J., and Bisby, L. A. 2010).

Gajdosova tested 8 slender concrete columns under eccentric loading. They found that NSM strengthening had higher impact on bearing capacity of slender columns under eccentric loading (Gajdosova, K., Bilcik, J. 2011).

Punurai considered five specimens of CFRP-confined RC slender columns under axial load and biaxial bending. By an analytic study and the comparison of the results with experimental results, they found that there was a good consistency between two studies and strengthening increased bearing capacity and ductility of slender columns (Punurai, W., Chen, J., Hsu, CTT. 2013).

Teng presented a theoretical model to predict the behavior of FRP-reinforced hoop RC slender columns and showed that FRP strengthening had high impact on the increase of bearing capacity in slender columns compared to that of short columns (Teng, J.G., Jiang, T. 2012).

There have been various studies on the behavior of FRP-reinforced columns in the technical literature. Most of these studies are regarding the effect of different parameters including the number of layers, applied fibers, location of fibers to the axle of columns, etc. on the improvement of strength and ductility properties (Rahai A, Akbarpour H. 2014; Lin H, Elisa D and Chen W, 2004).

The previous studies have been performed on the strengthening of FRP CR on short columns and under different conditions (Galal K, Arafa A, Ghobarah 2005).

Compared to the wide range of theoretical and empirical studies on FRP-reinforced short columns, there are a few studies on slender columns under eccentric loading namely bidirectional eccentric loading.

$\mathrm{Lu}$ (Lu, Y. Y., Li, N., Li, S., \& Ou, T. Y. 2015) evaluated the results of non-linear analysis of reinforced concrete columns under different conditions of combination of lateral load and axial loading based on the confinement effect.

The comparison between non-confinement columns and confinement columns based on using CFRP with the thickness $1.6 \mathrm{~mm}$ showed the increase of $64.4 \%$ of axial capacity of buckling in the confined specimen.

The effect of strengthening square columns with unidirectional and bidirectional CFRP fibers was evaluated by Tao (Tao Z, and Yu Q 2008) in an empirical study. This study showed that final strength of columns reinforced with CFRP transverse fibers had no considerable difference with unstrengthened columns. They showed that the considerable increase of bearing capacity of column was achieved by simultaneous strengthening with longitudinal and transverse fibers. In addition, they show that longitudinal fibers when bending controls the area behavior have high impact on the increase of bearing capacity of column.

Rocca (Rocca S, Galati N, Nanni A 2009) in an analytic and experimental study focused on the development of simplified interaction curve of transverse FRP-wrapped Reinforced Concrete (RC) columns at pressure-control region under uniaxial bending. The developed method in the mentioned study showed good consistency with the experimental results. IN the present study, the consistency relations are considered based on the above study.

Keykha (Keykha, A. H., Nekooei, M., Rahgozar, R., \& Narmashiri, K. 2015) evaluated the effect of strengthening short and slender columns using CFRP layers with two, four layer configurations in transverse and longitudinal directions on small scale specimens. This stud y showed that CFRP wrapping transversely instead of longitudinal increased the capacity of short columns but longitudinal fiber wrapping improved the behavior of slender columns and their ultimate strength like short columns.

Gao (Gao, X. Y., Balendra, T., \& Koh, C. G. 2013) tested 8 concrete columns with real scales under eccentric loading. The specimen included slender columns. Among all specimen, two non-strengthened (control specimen), two strengthened specimen with transverse CFRP, two specimen strengthened by Near Surface Mounted -NSM and two strengthened specimen by combined method of CFRP layers and NSM method. They found that NSM strengthening method had high impact on the increase of bearing capacity in which bending moment is considerable and their loading is eccentric. Shaat (Shaat, A., \& Fam, A. Z. 2013) presented a theoretical model to predict the behavior of FRP-reinforced RC. This model was used in the recent studies on the effect of FRP-wrapping RC.

The existing theoretical and experimental results to evaluate the effect of slender hoop columns via FRP confinement have acceptable precision from strength items (Hadi MNS. 2007; El Maaddawy M. 2009). From ductility changes, there is high difference between theoretical models and experimental results. It is assumed that 
the reason is the considerable effect of eccentric force on ultimate axial strain of the confined column and this is of great importance to predict the deformation capacity of reinforced column and it is not considered well in most of theoretical calculations.

Punurai (Punurai W, Chen J, Hsu CTT 2013) considered five specimens of transverse CFRP -confined square $\mathrm{RC}$ at small scale under axial loading and biaxial bending. By an analytic study and comparison of the results with empirical results, it was found that there was a good consistency between theoretical and empirical results. Their study showed that columns strengthening by the above method increased bearing capacity and ductility of slender columns. Rahai (Rahai A, Akbarpour H 2014) performed an experimental study of FRP-wrapped rectangular RC under eccentric loading. In this study, some parameters including FRP thickness, fibers orientation and axial eccentricity were considered. It was shown that by the increase of FRP thickness, strength and ductility were increased. The fibers orientation results were also compared. It was shown that by adding a longitudinal fiber instead of transverse fiber, ductility was increased.

This study performed an analysis on the finite elements of slender RC under axial loading and biaxial bending in which axial compressive and bending stresses were applied. Compared to the wide studies on confined short columns, the evaluation of the slender columns under eccentric loading is not adequate. In this study, slender RC under axial loading and biaxial bending with CFRP wrapping are modeled by Abaqus software with different slender ratios. The model was validated by the results of Gajdosova et al experiments (Gajdosova, K., Bilcik, J. 2011). Finally, a parametric study is performed based on the changes of slenderness parameter.

\section{Modeling Finite Elements}

In this study, finite element model is made using Abaqus 6.14 software. To simulate the concrete behavior, Concrete Damage Plasticity is used. This model is used to model the concrete behavior and other quasi-brittle materials in different structures (beam, truss, shell and full objects) in Abaqus software. This model uses the isotropic damage in linear range with the combination of isotropic tensile and plastic pressure to show non-linear behavior of concrete. This model can model the favorite loading conditions as cyclic loading and reduction of elastic stiffness is justified by considering plastic strain in tensile and in pressure. The introduced model for the concrete under damaged state is a continuous model based on plastic behavior and in the main fault mechanism in this model, the cracking of tensile and crushing in pressure price can be considered.

\subsection{Concrete}

The concrete strain-stress curve in pressure and tensile is used to predict the concrete behavior to the failure time. In pressure, the curve is divided into ascending and descending. In this study, to determine compressive strain-stress chart, Saenz model (Saenz, LP 1964) is used. The important equations of the mentioned model are as shown in Equation (1):

$$
\sigma_{c}=\frac{E_{c} \varepsilon_{c}}{1+\left(R+R_{E}-2\right)\left(\frac{\varepsilon_{c}}{\varepsilon_{0}}\right)-(2 R-1)\left(\frac{\varepsilon_{c}}{\varepsilon_{0}}\right)^{2}+R\left(\frac{\varepsilon_{c}}{\varepsilon_{0}}\right)^{3}}
$$

According to (Hu H-T, Schnobrich WC 1989), the existing parameters in Equation 1 are as shown in Equation 2.

$$
R=\frac{R_{E}\left(R_{\sigma}-1\right)}{\left(R_{\varepsilon}-1\right)^{2}}-\frac{1}{R_{\varepsilon}}, R_{E}=\frac{E_{c}}{E_{0}}, \quad E_{0}=\frac{f^{\prime}{ }_{c}}{\varepsilon_{0}}
$$

Also, $R_{\sigma}=4, R_{\varepsilon}=4, \varepsilon_{0}=0.0025$

The introduction of stress-strain of concrete in tensile is dedicated only to the definition of the effects after cracking indicating the tensile stiffening effects. The tensile stiffening effect indicates that the stiffness of a material is not zero suddenly after cracking and due to the involvement of particles and steel, the material can transfer load via the space between the cracks. In the modeling in this study, the relationship after the concrete cracking is assumed as linear to continue ultimate tensile strain 10 times more than cracking strain. Figure 1 shows the strain-stress relationship in uniaxial tensile (Mitofinejad, D.). 


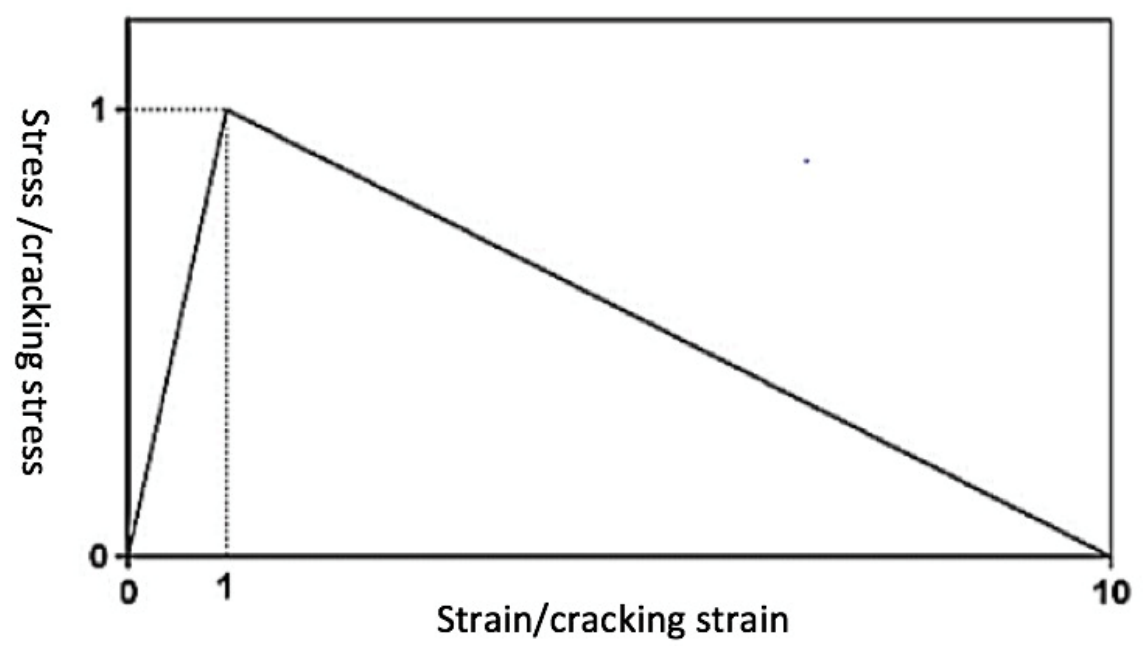

Figure 1. The stress-strain relationship of concrete in tensile

\subsection{Steel}

The steel behavior as elastic-plastic material with similar behavior in pressure and tensile can be considered.

\subsection{CFRP Composite}

6 unstrengthened experimental specimens with the diameter 10, height 20,40,60,80,100 cm are made (totally, 30). The study variables include the column slenderness (slenderness 2-10), reinforcement and non-reinforcement, one or two layers of reinforcement, CFRP carbon fiber configuration (configurations 45, 0.45, $0.90, \%, 0)$. The concrete strength, diameter of specimen and type of fiber are constant. 5 specimen are unstrengthened, 5 CFRP-strengthened, hoop (0), 5 specimen reinforced with two hoop layers (0), 5 specimen 45 degree, 5 specimen $0.90,5$ at reinforced 0.45 are tested. Also, stress-strain curve is considered as linear elastic to the failure of CFRP materials.

\subsection{Type of Applied Element}

To model concrete, a 8-node element Solid C3D8 with three degrees of freedom in each node is used. This type of element can consider plastic deformations and cracking in three orthogonal directions in each integrating point. In this study, time-dependent non-linear behavior including creeping and shrinkage are not modeled. To model steel rebars, Truss 2D two-node elements with three degrees of freedom in each node are used. Also, CFRP composites are modeled using S4R elements belonging to shell elements. Multi-purpose four-node shell element can reduce integral points to minimize the calculations and reduce analysis time. As the transverse shear effect is considered in this element, it is used for models with narrow and thick structure.

\subsection{The Interaction between Materials}

In this study, to model the behavior of a rebar and concrete, Embedded Region is used considering full consistency between concrete and steel. Also, it is assumed that there is a full cohesion between concrete and CFRF.

\section{Validation of Model}

To show the capability of the model, two samples of Gajdosova tests (Gajdosova, K., Bilcik, J. 2011) are used as validation criterion. As it was said in the introduction, Gajdosova performed his tests on slender RC under uniaxial eccentric loading reinforced with CFRP composite. In this study, C2, C6 specimens are modeled. C2 specimen is not strengthened and C6 is strengthened transversely and cross section. Figure 2 shows the details of both specimens.

The properties of CFRP materials, concrete, steep in the experiment specimen are shown in Tables 1, 2, 3, respectively.

The mentioned specimens are modeled completely in Abaqus software. Then, the non-linear static analysis under monotonic loading was performed to the failure of specimen. 
Table 1. The properties of CFRP materials

\begin{tabular}{ccccc}
\hline CFRP type & Tensile strength & Elasticity modulus & Ultimate strain & Fibers weight \\
\hline S\&P C-Sheet 240 & $3900 \mathrm{MPa}$ & $240 \mathrm{GPa}$ & $1.625 \%$ & $300 \mathrm{~g} / \mathrm{m}^{2}$ \\
\hline
\end{tabular}

Table 2. The properties of concrete materials

\begin{tabular}{lll}
\hline Properties & 28 days & 31 days \\
\hline Cubic specimen strength $(\mathrm{MPa})$ & 35.6 & 42.1 \\
cylinder specimen strength $(\mathrm{MPa})$ & 32 & 34.2 \\
static elasticity modulus $(\mathrm{GPa})$ & - & 36.8 \\
\hline
\end{tabular}

Table 3. The properties of steel materials

\begin{tabular}{ccc}
\hline Properties & Rebar 6 $(\mathrm{mm})$ & Rebar 10 $(\mathrm{mm})$ \\
\hline Yield strength (MPa) & 605 & 562 \\
Tensile strength (MPa) & 625 & 637 \\
static elasticity modulus (GPa) & 237 & 208 \\
Ultimate tensile strain (\%) & 6.64 & 10.75 \\
\hline
\end{tabular}

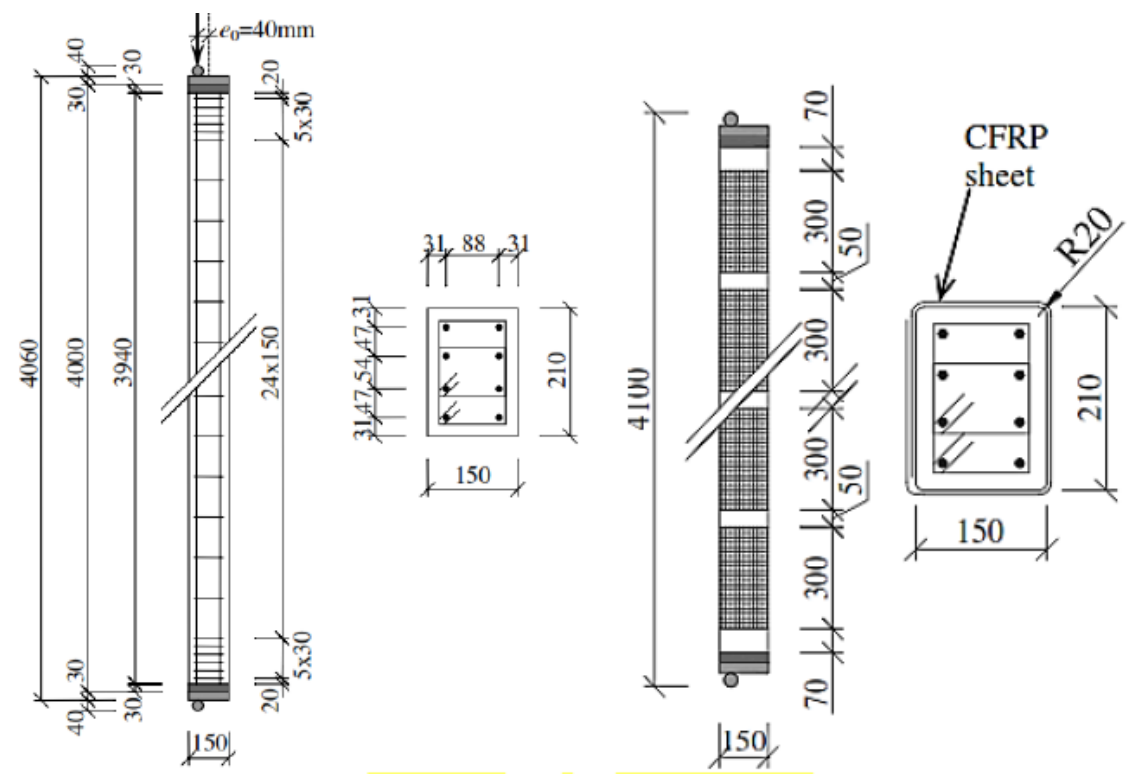

Figure 2. The details of $\mathrm{C} 2$, $\mathrm{C} 6$ specimen-dimensions in $\mathrm{mm}$

After the analysis of the models in software, we can observe the results as graphic or numerical data. The comparison of the results of finite element modeling and experimental results of Gajdosova (Gajdosova, K., Bilcik, J. 2011) is shown in Figure 3 for both specimens including the comparative chart of axial-bending for both specimen and it is also comparative failure image. By observation of charts of comparison of experimental and numerical results, we can find about the high precision of the modeling. Based on the model validation, in the next price, the models of parametric study are based on the goals of this study and can be analyzed. 
C2

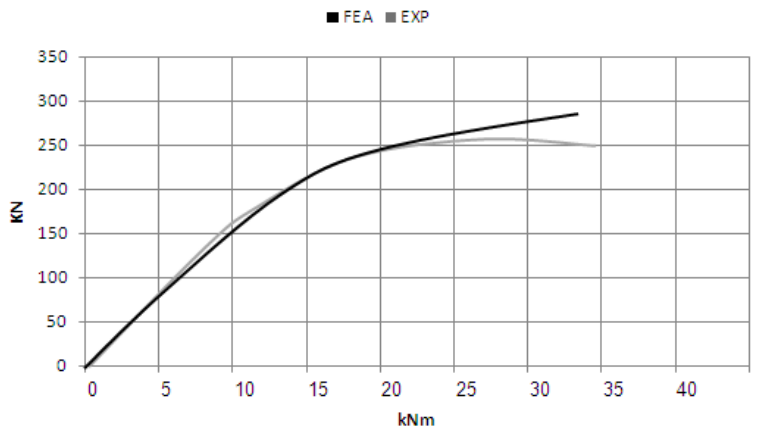

C6

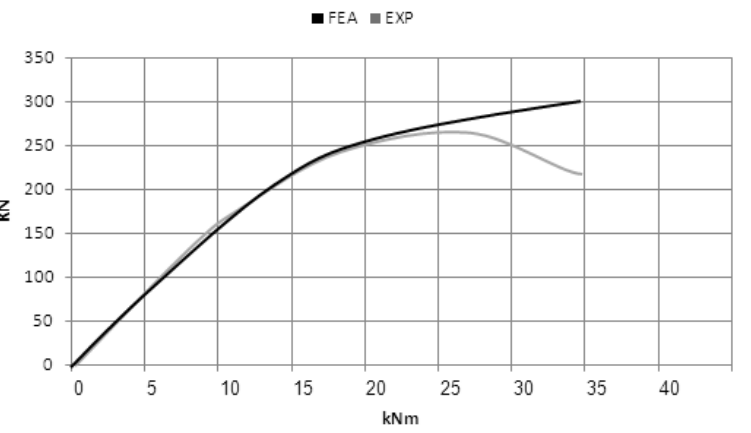

Figure 3. The comparison of the experimental and numerical modeling results, axial-bending moment force of specimens $\mathrm{C} 6, \mathrm{C} 2$

\section{Results}

After processing the data of experiments, strain-stress curve is plotted to show the effect of slenderness on strengthening and the effect of configuration of strengthening layers on strength and ductility of specimen.

\subsection{The Evaluation of the Effect of Layers Orientation}

Figure 4 shows that chart of axial load and biaxial bending based on axial strain of the specimen with the height 200 to $1000 \mathrm{~mm}$ separately to evaluate the effect of configuration of layers or type of strengthening. Figure 4 shows that plain sample is failed after reaching the strength maximum 25MP but at stress 20MP, the softening branching is about $0.5 \%$. This strain is occurred at stress level $85 \%$ of maximum strength and is defined as the ultimate strain of concrete. For the strengthened specimen, the behavior is totally different. To stress $25 \mathrm{MP}$, the behavior of strengthened and plain samples is not different considerably but then the strengthened samples continued their strength with a secondary ascending slope and by the rupture of composite wrapping, the specimen is ruptured.

Generally, the performance of confined concrete is based on the changes of volume in concrete. Wrapping is used on concrete if the concrete is inclined to expansion. In linear range of concrete behavior, as Poisson coefficient is constant, this volume change is constant. Thus, in the linear range, we shouldn't expect a considerable performance of the wrapping on concrete. Generally, before stress reaches compressive strength of unconfined concrete, the behavior of confined concrete and unconfined concrete is similar and after the stress reaches that limit, the wrapping starts and based on the stiffness of wrapping, stress ascends with higher secondary slope. In the specimen with hoop configuration, the secondary slope is almost similar and the stress takes an ascending path. Figure 4 shows that maximum strength with a hoop layer has reached from $25 \mathrm{MP}$ to $40 \mathrm{MP}$ and it shows the increase $60 \%$ in strength. In two hoop layers, with $100 \%$ increase, it has reached from $25 \mathrm{MP}$ to 50MP. In these two states, by wrapping rupture, the specimen experiences a sudden strength fall and achieves failure. The equivalent strain of wrapping rupture time in the state of one or two hoop is $1.4,2.2 \%$, respectively. This shows the increase of strain ductility to $2.8,4.4$ times more than that of plain concrete. The behavior of specimen with Axial-Hoop configuration and Angel-Hoop in comparison to only hoop configuration is not different only from maximum strength aspect but their failure is not sudden and it shows a softening behavior. The softening behavior can increase ductility and it is observed mostly in angel specimen. The behavior of samples with angel configuration has basic difference with other specimens.

As shown in Figure 4, their maximum strength has no significant difference with the plain samples but the failure of their ductility shows that by this configuration, without the increase of strength and creates brittle conditions, the energy dissipation of columns is increased double. This capability in columns strengthening against earthquake is of great importance. The discussed benefits are changed with the increase of slenderness as considered in the next section. 


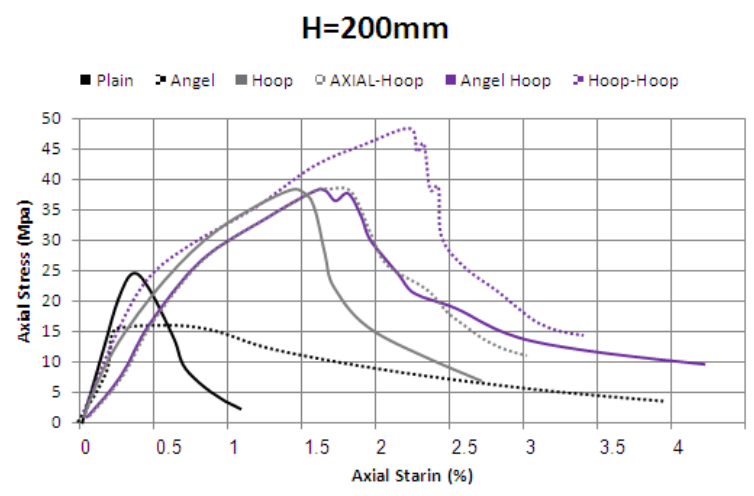

$\mathrm{H}=600 \mathrm{~mm}$

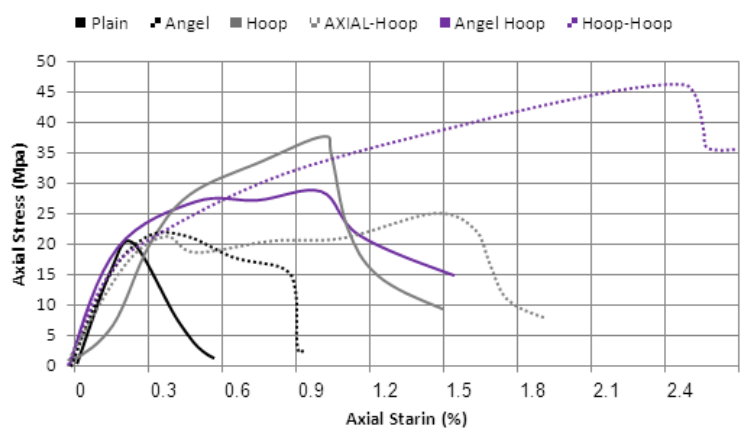

$\mathrm{H}=400 \mathrm{~mm}$

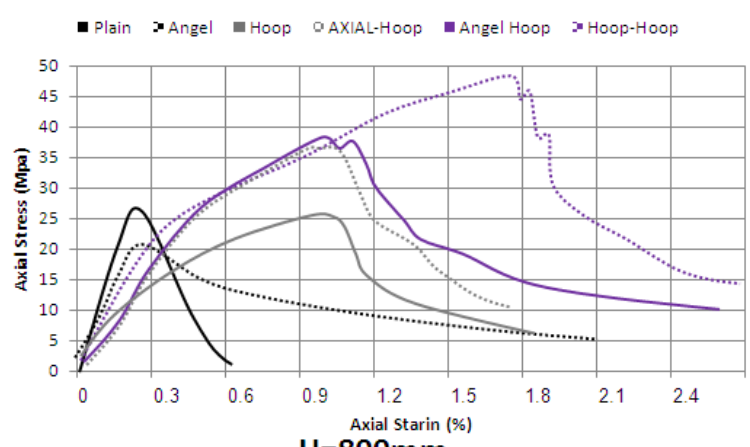

$\mathrm{H}=800 \mathrm{~mm}$

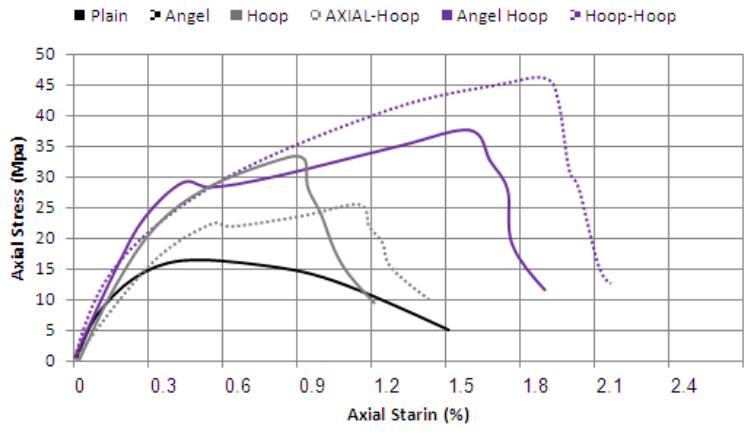

$\mathrm{H}=1000 \mathrm{~mm}$

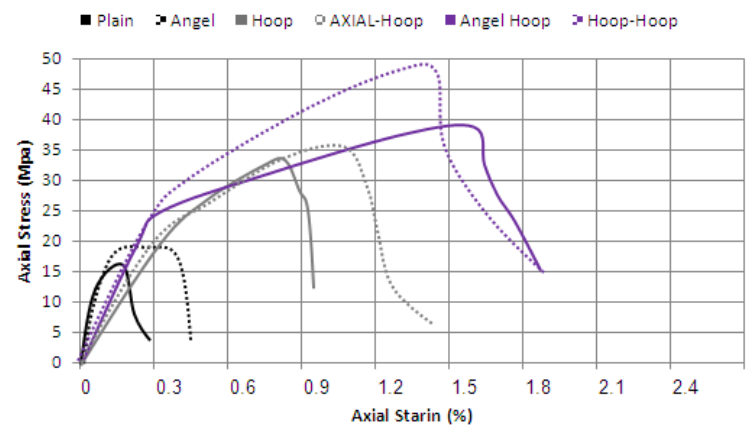

Figure 4 . The effect of strengthening on the specimen with different heights

\subsection{The Evaluation of Slenderness Effect}

In this section, the effect of slenderness on stress-strain behavior of different specimens with different strengthening conditions is studied. It is observed that for specimens with the height $200,400 \mathrm{~mm}$, the maximum strength is similar but by the increase of slenderness, maximum strength is reduced. At the height $1000 \mathrm{~mm}$, the strength with about $35 \%$ reduction reaches $16 \mathrm{MP}$.

It is worth to mention that the plain specimen with the height $800 \mathrm{~mm}$ is damaged during transportation and it is not tested. The effect of slenderness on ductility of these specimens is higher than on strength. As shown in Figure 5, by the increase of specimens from 200 to $1000 \mathrm{~mm}$, the ultimate strain at the level 5MP is reduced from $0.85 \%$ to $0.25 \%$.

In other words, by 5 times increase of slenderness, ductility is reduced to $1 / 3$ and this shows the brittle fracture of plain specimens. Figure 5 shows the slenderness effect in specimens with one or two layer hoop. By the increase of slenderness, the maximum strength is not different. In other words, hoop direction can eliminate the slenderness effect on strength. From ductility aspects, by the increase of slenderness, ultimate strain has a slow descending trend compared to that of plain specimens. In other words, using hoop direction can improve slender specimens failure and increase energy dissipation.

Figure 5 shows the slenderness effect in strengthened specimens' behavior with hoop-longitudinal, hoop-angel orientations. It is observed that like hoop orientation, the mentioned orientations cause that the ultimate strength 
of slender columns is at the same level as the short columns and energy dissipation is reduced little. Figure 5 shows the effect of slenderness on angle specimens. It is observed that by the increase of slenderness, angle orientation can keep strength at constant level. However, in terms of ultimate strain, this orientation cannot increase ductility as other orientations. Generally, the positive effect of angel layers on short specimens is not seen in the slender specimens. It can be said that great deformations at low stress can be based on angel orientation in long specimens and can increase the secondary moments and early failure is created. In hoop orientation, great deformations are occurred at levels with high stress and the area under stress-strain chart is increased and energy dissipation is increased.

Plain

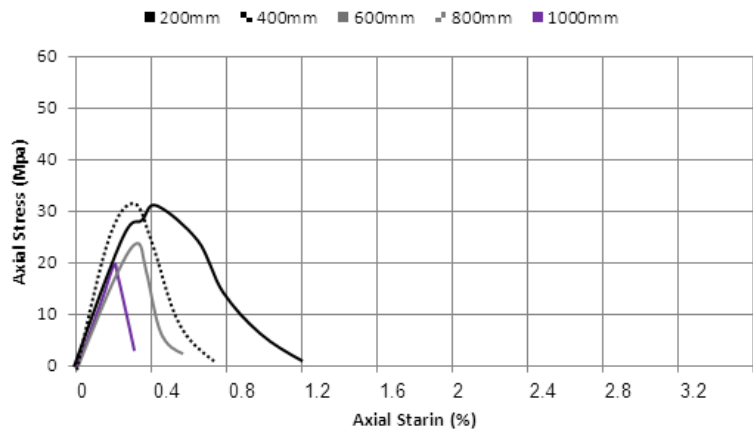

2-HooP $0^{\circ} / 0^{\circ}$

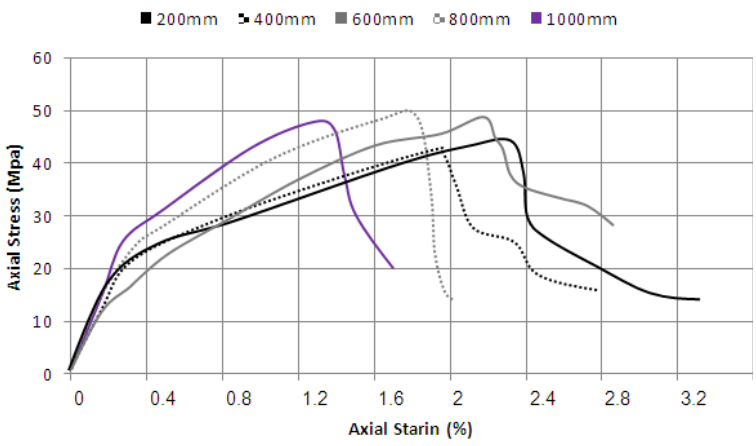

Angel-HooP 45\% $/ 0^{\circ}$

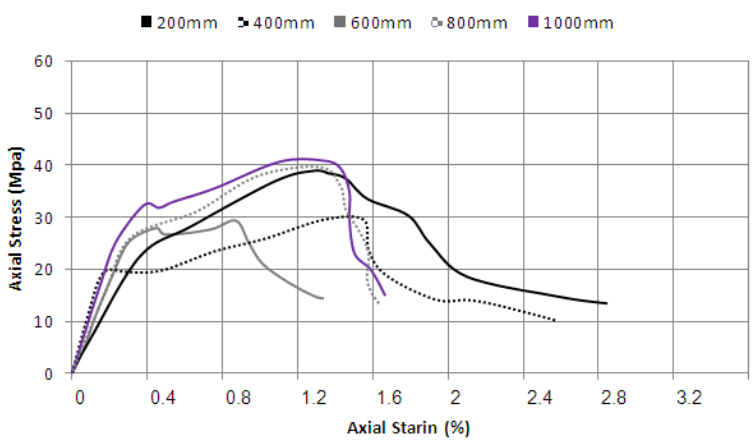

HooP $0^{\circ}$

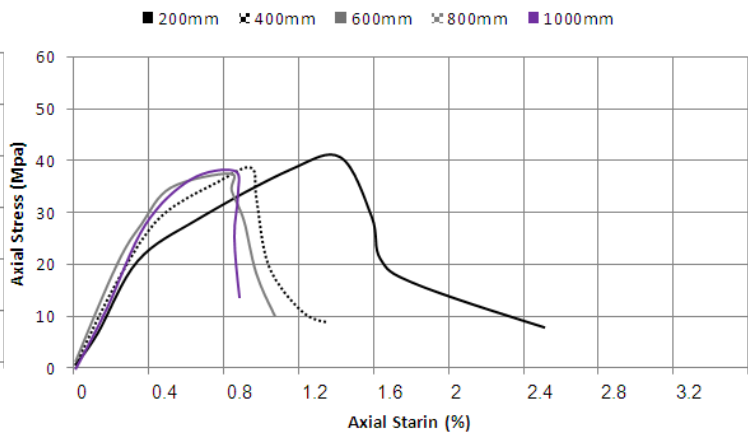

Axial-HooP 90\% $/ 0^{\circ}$

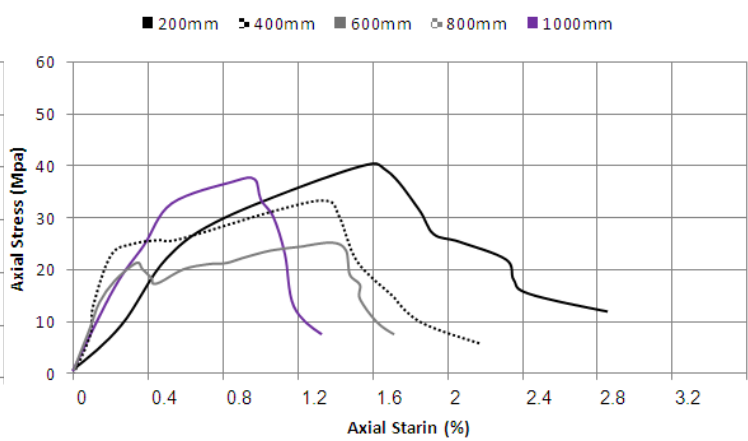

Angel 45 ${ }^{\circ}$

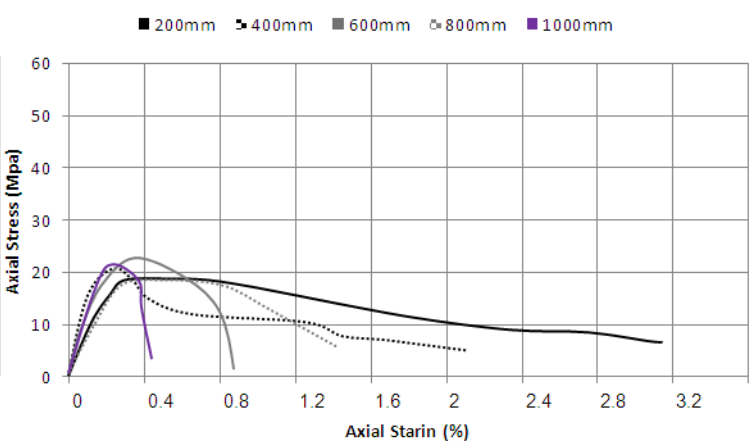

Figure 5. The slenderness effect on specimens strengthened with different layers

\section{Conclusion}

To evaluate the slenderness effect on CFRP-reinforced columns, 30 non-strengthened circular columns with the diameter 100mm and heights 200, 400,600, 800,1000mm (slenderness 1-10) are made and strengthened with unidirectional CFRP composites. In each slenderness, a control specimen (plain) and 5 strengthened specimens with different orientations of fibers $(0,0.0,90.0,0.45,45)$ are tested under axial loading and biaxial bending to the ultimate failure. In this study, after validation of finite elements model by experimental works, a parametric 
study is performed based on the change of slenderness parameter. The results showed that in plain specimens, by the increase of slenderness from $1-10$, strength and ductility reduced to $35,65 \%$, respectively. Strengthening slender specimens with CFRP composites causes that strength is kept at the level of short specimens and ductility is reduced slowly. Strength is kept at all orientations of reinforced fibers but the strengthening of hoop in ductility is much effective than that of angel orientation. Thus, using CFRP composites is an effective method to improve the performance of slender columns in terms of increase of strength and ductility namely against seismic loads. The results showed that CFRP-strengthened RC increased bearing capacity of mentioned columns under biaxial bending. Based on the shortage of experimental data on slender columns and high costs of experimental works, by similar studies, we can eliminate the problems. By the increase of slenderness, the deformation of columns was increased and the effect of passive confinement of composite was used mostly and strengthening effect was also increased.

\section{References}

Cheng, H. L., Sotelino, E. D., \& Chen, W. F. (2004). Sensitivity Study and Design Procedure for FRP Wrapped Reinforced Concrete Circular Columns. International Journal of Applied Science and Engineering, 2(2), 148-162.

Desayi, P., \& Krishnan, S. (1964, March). Equation for the stress-strain curve of concrete. In Journal Proceedings (Vol. 61, No. 3, pp. 345-350).

Fitzwilliam, J., \& Bisby, L. A. (2010). Slenderness effects on circular CFRP confined reinforced concrete columns. Journal of Composites for Construction, 14(3), 280-288. https://doi.org/10.1061/(ASCE)CC.1943-5614.0000073

Gajdošová, K., \& Bilčík, J. (2011). Slender reinforced concrete columns strengthened with fibre reinforced polymers. Slovak Journal of Civil Engineering, 19(2), 27-31. https://doi.org/10.2478/v10189-011-0010-3

Galal, K., Arafa, A., \& Ghobarah, A. (2005). Retrofit of RC square short columns. Engineering Structures, 27(5), 801-813. https://doi.org/10.1016/j.engstruct.2005.01.003

Gao, X. Y., Balendra, T., \& Koh, C. G. (2013). Buckling strength of slender circular tubular steel braces strengthened by CFRP. Engineering structures, 46, 547-556. https://doi.org/10.1016/j.engstruct.2012.08.010

Hadi, M. N. (2007). The behaviour of FRP wrapped HSC columns under different eccentric loads. Composite Structures, 78(4), 560-566. https://doi.org/10.1016/j.compstruct.2005.11.018

Hu, H. T., \& Schnobrich, W. C. (1989). Constitutive modeling of concrete by using nonassociated plasticity. $\begin{array}{lllll}\text { Journal of Materials in Civil } & \text { Engineering, } & \text { 1(4), }\end{array}$ https://doi.org/10.1061/(ASCE)0899-1561(1989)1:4(199)

Jiang, T., \& Teng, J. G. (2012). Theoretical model for slender FRP-confined circular RC columns. Construction and building materials, 32, 66-76. https://doi.org/10.1016/j.conbuildmat.2010.11.109

Keykha, A. H., Nekooei, M., Rahgozar, R., \& Narmashiri, K. (2015). Investigation of load Increment in Hollow Steel short and slender Columns Strengthened using CFRP.

Lu, Y. Y., Li, N., Li, S., \& Ou, T. Y. (2015). Slender RC columns strengthened with combined CFRP and steel jacket under axial load. Steel and Composite Structures, 19(5), 1077-1094. https://doi.org/10.12989/scs.2015.19.5.1077

Maaddawy, T. E. (2009). Strengthening of eccentrically loaded reinforced concrete columns with fiber-reinforced polymer wrapping system: Experimental investigation and analytical modeling. Journal of Composites for Construction, 13(1), 13-24. https://doi.org/10.1061/(ASCE)1090-0268(2009)13:1(13)

Mirmiran, A., Shahawy, M., \& Beitleman, T. (2001). Slenderness limit for hybrid FRP-concrete columns. $\begin{array}{lllll}\text { Journal of Composites for } & \text { Construction, } & \text { 5(1), } & \text { 26-34. }\end{array}$ https://doi.org/10.1061/(ASCE)1090-0268(2001)5:1(26)

Mitofinejad, D. (n.d.). RC structures (Vol. 1, 12th ed.). Arkan Danesh publications. Isfahan, 1.

Pan, J. L., Xu, T., \& Hu, Z. J. (2007). Experimental investigation of load carrying capacity of the slender reinforced concrete columns wrapped with FRP. Construction and Building Materials, 21(11), 1991-1996. https://doi.org/10.1016/j.conbuildmat.2006.05.050

Punurai, W., Hsu, C. T. T., Punurai, S., \& Chen, J. (2013). Biaxially loaded RC slender columns strengthened by $\begin{array}{lllll}\text { CFRP composite fabrics. } & \text { Engineering } & \text { Structures, } & 46, & \text { 311-321. }\end{array}$ https://doi.org/10.1016/j.engstruct.2012.07.014 
Rahai, A., \& Akbarpour, H. (2014). Experimental investigation on rectangular RC columns strengthened with CFRP composites under axial load and biaxial bending. Composite Structures, 108, 538-546. https://doi.org/10.1016/j.compstruct.2013.09.015

Rocca, S., Galati, N., \& Nanni, A. (2009). Interaction diagram methodology for design of FRP-confined reinforced concrete columns. Construction and Building Materials, 23(4), 1508-1520. https://doi.org/10.1016/j.conbuildmat.2008.06.010

Shaat, A., \& Fam, A. Z. (2013). Erratum for "Slender Steel Columns Strengthened Using High-Modulus CFRP Plates for Buckling Control" by Amr Shaat and Amir Z. Fam. Journal of Composites for Construction, $18(1), 2-12$.

Tamuzs, V., Tepfers, R., Zile, E., \& Valdmanis, V. (2007). Stability of round concrete columns confined by composite wrappings. Mechanics of Composite Materials, 43(5), 445-452. https://doi.org/10.1007/s11029-007-0042-y

Tao, Z., \& Han, L. H. (2007). Behaviour of fire-exposed concrete-filled steel tubular beam columns repaired with CFRP wraps. Thin-walled structures, 45(1), 63-76. https://doi.org/10.1016/j.tws.2006.11.004

Tao, Z., \& Yu, Q. (2008). Behaviour of CFRP-strengthened slender square RC columns. Magazine of Concrete Research, 60(7), 523-533. https://doi.org/10.1680/macr.2008.60.7.523

\section{Copyrights}

Copyright for this article is retained by the author(s), with first publication rights granted to the journal.

This is an open-access article distributed under the terms and conditions of the Creative Commons Attribution license (http://creativecommons.org/licenses/by/4.0/). 